\title{
Knowledge, Practice and Barrier Towards Emergence Contraceptive Usage Among Female University Students at Kilimanjaro Region in Tanzania.
}

\section{Tonny J. Mariki ( $\nabla$ tonnyelinamu@gmail.com )}

KILIMANJARO CHRISTIAN MEDICAL UNIVERSTY COLLEGE(KCMUCo)

Euphurasia J. Mbuya

KILIMANJARO CHRISTIAN MEDICAL UNIVERSTY COLLEGE(KCMUCo)

Erick J. Mkojera

KILIMANJARO CHRISTIAN MEDICAL UNIVERSTY COLLEGE(KCMUCo)

Caroline Amour

KILIMANJARO CHRISTIAN MEDICAL UNIVERSTY COLLEGE(KCMUCo)

Innocent Mboya

KILIMANJARO CHRISTIAN MEDICAL UNIVERSTY COLLEGE(KCMUCo)

Sia E. Msuya

KILIMANJARO CHRISTIAN MEDICAL UNIVERSTY COLLEGE(KCMUCo)

\section{Research Article}

Keywords: knowledge, barrier, emergence contraception

Posted Date: February 11th, 2022

DOI: https://doi.org/10.21203/rs.3.rs-1300549/v1

License: (c) (i) This work is licensed under a Creative Commons Attribution 4.0 International License.

Read Full License 


\section{Abstract}

Background: Unplanned pregnancy is major public health concern. Globally unintended pregnancies account for about $40 \%$ of all pregnancies annually. The problem is more in developed countries in which nearly half of all pregnancies are unintended. In Tanzania over 20 women die each day due to the complication of unplanned pregnancy and childbirth which contribute to high maternal mortality rate. Though EC can prevent unplanned pregnancies by nearly $95 \%$ to $99 \%$ but the practice is still very low in Africa as well as in Tanzania despite some of the study shown that there is moderate knowledge. Therefore, the current study aiming of assessing knowledge, practice and barrier or challenges which face female university students in using EC.

Method: A cross-sectional study design was conducted among 365 female students at Kilimanjaro Christian Medical University College (KCMUCO), Mwenge Catholic University (MWECAU) and Moshi cooperative University (MOCU) in Kilimanjaro region. A simple random sampling technique was used to select study participants. Self-administered questionnaires were used during data collection.

Results: About (65.7\%) of the female university students had ever heard of EC and more than half of them had knowledge on when to use EC (54.4\%), where to obtain $(58.7 \%)$ and time for EC to be taken (41.5\%). Moreover about $75.6 \%$ of female university students in this study reported never use emergency contraceptives (EC) while $24.4 \%$ reported having ever used emergency contraceptive and among $24.4 \%$ EC users reported that $90.2 \%$ use EC pills method. On the other hand, common barriers toward EC use reported by female university students were fear of side effects, personal barrier, and religion opposition $39.4 \%, 31.9 \%$ and $12.8 \%$ respectively.

Conclusions. This study found that majority $65.7 \%$ of female university students had ever heard of emergence contraceptive (EC) in their lives. Practice of EC is still very low among female students where by only $24.4 \%$ reported having ever used emergency contraceptive. Fear of side effect and personal barrier were mostly reported as the common barrier by the female student towards EC usage $39.4 \%$, $31.9 \%$ respectively. Thus, there is an urgent need to educate the female university students about EC.

\section{Background}

Emergence contraceptives (EC) is a method of contraception which is mainly used by a person following unprotected sexual intercourse, missing of regular contraceptives methods or non-use of contraceptives methods for the aim of preventing the unintended pregnancy or unplanned pregnancy(1) Mode of action of emergence contraceptive is working by either preventing the fusion of male sperm and female eggs to occur, to interfere the transportation of male sperms and female eggs through fallopian tube where the fertilization is normally take place, to prevent the implantation of an embryo. But the emergence contraceptive does not have any effect on already established pregnancy(2)

Globally every year there are about 250 million of pregnancies occur and among these one third of them are unintended pregnancy and $20 \%$ of these unintended pregnancies they undergo induced abortion. In 
low income country there are about 182 pregnancies occurred and more than one third of this pregnancy are unintended. $19 \%$ of this unintended will be induced abortion and $11 \%$ of this undergoes unsafe abortion(3)About 25 million insecure abortions take place each year, almost in the developed country and the risky of dying is highest in Africa(4) 21.6 million of unintended pregnancy occur in Africa alone likewise in Eastern Africa there were 8.85 million of unintended pregnancy each year compared to the 99.1 million of unintended pregnancy which occurred worldwide per year and $56 \%$ of all this unintended pregnancy in Africa ended in unsafe abortion(5)

About $20 \%$ of Tanzanian population is between 15 and 24 years of age(6) Most youth join universities between this age among them there are sexual active girls which faced some challenges in accessing contraceptives then married women due to stigma attached to their sexual activities before marriage, and cause them to fall in unwanted and teen pregnancies and unsafe abortions(6)

Despite there is high burden of unplanned pregnancy in Tanzania as WHO estimated that every year 1 million of female face unintended pregnancy. But unplanned pregnancy is highly preventable when there is uptake of EC wherever the need arises. This study however is conducted to assess the knowledge, practice and barrier towards emergence contraceptives usage among female university students since many studies has been conducted shows that the level of knowledge about EC is high, however the practice of EC is still low among female university students despite that their knowledgeable.

\section{Materials And Methods}

\section{Study population and study areas}

Study population was all female student in all course in the selected universities. Study took place in in three universities among four universities which are in Kilimanjaro region this including Kilimanjaro Christian Medical University college (KCMUCO) Moshi cooperative University (MOCU) and Mwenge Catholic University (MWECAU).

\section{Data collection method.}

The data were collected using Self-administered questionnaires and the data collectors distributed questionnaires to each participant. Self-administered questionnaire created a room for a participant to be free answering sensitive questions like those involving reproductive history in which it is very difficult to answer when is directly asked by investigator.

\section{Study procedure}

Ethical approval from the local review board, permission from Kilimanjaro Christian Medical University College (KCMUCO), Moshi cooperative University (MOCU) and Mwenge Catholic University (MWECAU) were obtained before data collection. Researchers/ data collectors visited the selected universities, meet dean of students, introduced themselves, and clearly explained the purpose and duration, as well as who should participate in the study. Then after the researcher obtained the number of female students in each 
university and planned for data collection. On the day of data collection, the researchers administered informed consent to all eligible participants and addressed all questions before conducting the research. Participation in this study was voluntary; therefore, information's were collected from all consenting female students by using self-administered questionnaire. During the data collection, respondents were free not to respond to any particular question and to drop any time they felt so. After the collection of data, researchers thanked respondents for their time and information they provided. All questionnaires were checked for completeness immediately before respondents left the room.

\section{Data analysis}

The statistical data were analyzed using statistical package for social science (SPSS) version 20. Numerical variable was summarized using measure of central tendency with their corresponding measure of dispersion while categorical variable was summarized using frequency/proportion.

\section{Results}

\section{Characteristic of participant}

The median age of 365 female university students participated in this study was 22 (IQR 21-22) years. Most of the participants $92.5 \%$ were in the age group $15-25$ years and $7.5 \%$ belonged to age $26-35$ years. The majority of the female students $90.8 \%$ were unmarried where $8.6 \%$ were married and $0.6 \%$ was divorced. Among total participants a half $50.6 \%$ were from non-medical colleges and $49.4 \%$ were from medical colleges. About $82.6 \%$ of the participants were taking degree education level and more than half $52.2 \%$ of them were first year students. Most of the respondents $54.3 \%$ had urban background and the remaining $45.7 \%$ had rural backgrounds (Table 1 ).

Table 1 : Participant background characteristics $(\mathrm{N}=365)$ 


\begin{tabular}{|c|c|c|}
\hline Variables & Frequency & Percentage \\
\hline \multicolumn{3}{|l|}{ Age (years) } \\
\hline $15-25$ & 334 & 92.5 \\
\hline $26-35$ & 27 & 7.5 \\
\hline Median (IQR) & 22 & $(21.0,23.0)^{a}$ \\
\hline \multicolumn{3}{|c|}{ Level of education $(n=363)^{\star}$} \\
\hline Certificate & 6 & 1.7 \\
\hline Diploma & 57 & 15.7 \\
\hline Degree & 300 & 82.6 \\
\hline \multicolumn{3}{|c|}{ Department of affiliation $(n=354)^{\star}$} \\
\hline Medical & 175 & 49.4 \\
\hline Non medical & 179 & 50.6 \\
\hline \multicolumn{3}{|c|}{ Year of study $(n=364) *$} \\
\hline First year & 190 & 52.2 \\
\hline Second year & 123 & 33.8 \\
\hline Third year & 51 & 14.0 \\
\hline \multicolumn{3}{|c|}{ Marital status $(n=347) *$} \\
\hline Unmarried & 315 & 90.8 \\
\hline Married & 30 & 8.6 \\
\hline Divorced & 2 & 0.6 \\
\hline
\end{tabular}

*Variables with missing values. ${ }^{\text {IInterquartile range }}$

\section{Participants knowledge of emergence contraceptive (EC)}

The vast majority $65.7 \%$ of female university students who participated in this study had ever heard of emergence contraceptive (EC) in their lives. Among $65.7 \%$ participants who knew about EC $51.9 \%$ of them 
mentioned that formal education was their source of information and $14.5 \%$ mentioned internet. A majority of the participants $41.5 \%$ respond that EC should be taken within 72 hours after unprotected sex, where $14.7 \%$ reported that EC should be taken immediately after sex. About $58.7 \%$ of the participants mentioned hospital as the place where they can obtain EC and $22.3 \%$ of them mentioned pharmacy. More than half of them $68.0 \%$ female students didn't know about the correct time interval between the doses of EC practice, while $(22.2 \%$ and $9.8 \%)$ mentioned that the recommended time intervals between the doses for EC use are twelve hours and forty hours respectively (Table 2).

Table 2: Knowledge of emergence contraceptive use $(\mathrm{N}=365)$ 
Ever heard of emergence contraceptive $(n=364)$ *

\begin{tabular}{lll}
\hline Yes & 239 & 65.7 \\
\hline No & 125 & 34.3 \\
\hline Source of information(n=241)* & & \\
\hline Formal education & 125 & 51.9 \\
\hline Media & 20 & 8.3 \\
\hline Magazine & 2 & 0.8 \\
\hline Internet & 35 & 14.5 \\
\hline Health facilities & 29 & 12.0 \\
\hline Partner & 4 & 1.7 \\
\hline Friends & 26 & 10.8 \\
\hline Where to obtain EC (n=346)* & & \\
\hline Hospital & 203 & 58.7 \\
\hline Social workers & 6 & 1.7 \\
\hline Private clinic & 9 & 2.6 \\
\hline Supermarket & 1 & 0.3 \\
\hline Pharmacy & 77 & 22.3 \\
\hline Don't know & 48 & 13.9 \\
\hline It's impossible to obtain & 2 & 0.6 \\
\hline
\end{tabular}

When to use EC ( $n=298)$ *

\begin{tabular}{lll}
\hline Post rape & 162 & 54.4 \\
\hline Back up on condom break & 65 & 21.8 \\
\hline Forgotten oral contraceptive pills & 71 & 23.8 \\
\hline Time for EC pills to be taken ( $\mathrm{n}=342) *$ & & \\
\hline Immediately after sex & 64 & 18.7 \\
\hline At any time before the first day & 17 & 5.0 \\
\hline Within 48 hours/two days & 37 & 10.8 \\
\hline
\end{tabular}




\begin{tabular}{lll} 
Within 72 hours / three days & 142 & 41.5 \\
\hline Within one week & 2 & 0.6 \\
\hline I don't know & 80 & 23.4 \\
\hline Recommended intervals between doses $(\mathbf{n}=338) *$ & & \\
\hline Twelve hours & 75 & 22.2 \\
\hline Forty hours & 33 & 9.8 \\
\hline I don't know & 230 & 68.0
\end{tabular}

*Variables with missing values.

\section{Participant Practice of emergence contraceptive}

About $75.6 \%$ of participants in this study reported never use emergency contraceptives (EC) while $24.4 \%$ reported having ever used emergency contraceptive. Among $24.4 \%$ EC users reported that $90.2 \%$ use EC pills as the method of EC. Out of the total user, $54.8 \%$ were recommended by partner to use EC. Among the reasons reported for using EC included timing of menstruation was miscalculated (24.7\%), condom broke or slipped (18.8\%), withdrawal fail (15.3\%) and no use of other contraceptives (14.1\%) (Table3).

Table 3 : Participant Practice of emergence contraceptive ( $\mathrm{N}=365)$ 


Variables Frequency Percentage

\section{Ever use any EC ( $n=352)$ *}

\begin{tabular}{lll}
\hline Yes & 86 & 24.4 \\
\hline No & 226 & 75.6 \\
\hline Which method of EC ( $\mathbf{n}=\mathbf{8 2}$ * & & \\
\hline Emergence contraceptive pills & 74 & 90.2 \\
\hline Cooper bearing intrauterine device & 8 & 9.8 \\
\hline Who recommended it for you ( $\mathbf{n = 8 2 ) *}$ & & \\
\hline Friends & 17 & 20.2 \\
\hline Partner & 46 & 54.8 \\
\hline Through internet & 1 & 1.2 \\
\hline Health professional & 14 & 16.7 \\
\hline Don't remember & 6 & 7.1 \\
\hline Reason for using EC $(\mathbf{n}=85) *$ & & \\
\hline No use of other contraceptive & 12 & 14.1 \\
\hline Timing miscalculation & 21 & 24.7 \\
\hline Condom broke or slipped & 16 & 18.8 \\
\hline Missed pills & 7 & 8.2 \\
\hline Forced to have sex & 2 & 2.4 \\
\hline The withdrawal fails & 13 & 15.3 \\
\hline I don't remember & 14 & 16.5 \\
\hline
\end{tabular}

Variable with missing values*

\section{Participants barrier towards EC usage}


About $39.4 \%$ of the participants in this study reported that fear of side effects as common barrier toward EC use, also $31.9 \%$ of them reported personal barrier and $12.8 \%$ of them mentioned religion opposition as a barrier toward EC use. Worries about embarrassment, opposition from parents, distrust to health workers, no privacy and not friendly $1.6 \%, 2.5 \%, 2.2 \%, 3.1 \%$, and $6.6 \%$ respectively were expressed as a minor hindrance toward use EC by the participants (Table 4).

Table 4 : Participants barrier towards EC usage $(\mathrm{N}=365)$.

Variables

Frequency Percentage

Barriers of not using emergence contraceptive $(n=320) *$

\begin{tabular}{lll}
\hline Personal barriers & 102 & 31.9 \\
\hline Religion opposition & 41 & 12.8 \\
\hline Fear of side effects & 126 & 39.4 \\
\hline Embarrassment & 5 & 1.6 \\
\hline Opposition from parents & 8 & 2.5 \\
\hline Distrust to health workers & 7 & 2.2 \\
\hline No privacy & 10 & 3.1 \\
\hline Not friendly & 21 & 6.6
\end{tabular}

Variables with missing values*

\section{Discussion}

The presented data assess the knowledge, practice and barriers toward emergency contraceptives usage among female university students in Kilimanjaro Region. The results of this study shows that majority $(65.7 \%)$ of the female university students had ever heard of EC and more than half of them had adequate knowledge on when to use EC (54.4\%), where to obtain (58.7\%) and time for EC to be taken (41.5\%). Moreover about $75.6 \%$ of female university students in this study reported never use emergency contraceptives (EC) while $24.4 \%$ reported having ever used emergency contraceptive and among $24.4 \%$ EC users reported that $90.2 \%$ use EC pills method. On the other hand, common barriers toward EC use reported by female university students were fear of side effects, personal barrier, and religion opposition $39.4 \%, 31.9 \%$ and $12.8 \%$ respectively.

In this study, the majority of the participant ever heard about emergence contraceptive. This findings are higher compared to those from other studies $(3,7,8)$ where nearly half of the participants heard about emergence contraceptive. The higher awareness in this study is probably due to wide availability of 
information about EC in the internet, newspapers, radio, television health programs and also EC methods are widely used by females. The estimate in this study is lower than a study conducted in Ethiopia(9) This could be explained in fact that in Ethiopia when EC was introduced, sustainable effort were made to educate about EC at any level of providers included pharmacy, hospital and health care providers. This shows a need to strengthen awareness and mass campaigns that may potentially increase the level of awareness about EC.

In this study showed that formal education and internet to be the most source of information concerning emergence contraceptive stated by participants. Different studies identified different sources providing information on emergence contraceptive. Accordingly, the most commonly stated sources of information included mass media, books/magazine and friend/partner $(10,11)$ These evidences clearly show that method mix (formal education, combination of mass media and internet) has to be used to make emergence contraceptive information as widely disseminated as possible so as to increase awareness of youth and adolescence in universities as well as community at large.

In this study $41.5 \%$ of the respondents mentioned the correct time for EC to be taken (maximum $72 \mathrm{Hrs}$ ) and $22.2 \%$ mentioned the correct time interval between the doses $(12 \mathrm{Hrs})$. However this is higher than that $28.3 \%$ mentioned correct time for EC to be taken and 14.8\% mentioned correct time interval between doses (12) and lower than $51.14 \%$ obtained by(13) This difference might be attributed due to the differences in provision of sexual and reproductive health education at schools and higher learning institutions as well better practice off opening and free discussion on sex and sexuality among female students. This finding reveals that comprehensive knowledge about emergence contraceptive is lacking among female university student at Kilimanjaro region.

In this study $24.4 \%$ of the respondents reported to have used emergence contraceptive. Similarly in a study done in India among medical students showed that $3.7 \%$ of the participants have used emergence contraceptive(14) and $12.5 \%$ obtained by(15). This lower utilization rate off emergence contraceptive suggested by other studies could be due to lack of information, partner disagreement, fear of being seen by others, fear of side effect and becoming infertile. Moreover among $24.4 \%$ of EC users in this study, $54.8 \%$ reported that they were recommended by their partners and $20.2 \%$ reported that they were recommended by their friends to use it. Therefore, this shows a need to introduce reproductive health education and must be implemented for this group in order to increase the uptake of EC methods so as to avoid the high rate of unwanted pregnancy.

\section{Conclusions}

This study showed that majority $65.7 \%$ of female university students had ever heard of emergence contraceptive (EC) in their lives. Practice of EC is still very low among female students where by only $24.4 \%$ reported having ever used emergency contraceptive, among those EC users reported that $90.2 \%$ of them use EC pills as the methods of emergence contraception. Fear of side effect and personal barrier were mostly reported as the common barrier by the female student towards EC usage $39.4 \%, 31.9 \%$ 
respectively. Thus, there is an urgent need to educate the female university students about EC. Carefully designed education programs and the promotion of EC in the existing student's health clinic on campuses as well as discussion during orientation programs need to address the issue of unwanted pregnancies.

\section{Declarations}

\section{Acknowledgements}

Thanks to all participant that took place in our study this including all university and our supervisors.

\section{Authors contributions}

TJM, EJM, EJM made a substantial contribution to design the research concept, data acquisition, data processing, data analysis, reporting writing and manual script drafting revising's, TM, CA played a vital role in supervision and critical revision of the manuscript. Both authors read and approved the manual script.

\section{Funding}

Not applicable.

\section{Availability of data and materials.}

The SPSS datasets used and/or analyzed during the current study are available from the corresponding author on reasonable request.

\section{Ethical consideration}

Before data collected, Ethical clearance was obtained from Kilimanjaro Christian Medical University College (KCMUCo), ethical review committee, and institute of public health department. Informed consent was obtained from the participants before enrollment in the study. The consent form written in the English language contained a description of study objectives, nature of the participant's involvement, risk and benefit and confidentiality of the study, was provided to the participants. Participants were requested to read the consent form carefully before start to fill questionnaire and the participation in this study was voluntary. Participants were allowed to refuse to answer any question and terminate the interview when they desired. Confidentiality of information was ensured by removing personal identifiers from the questionnaire. Respondents were protected against any possible adverse repercussions from participating in the study.

\section{Consent for publication}

Necessary permission for publication was obtained from ethical committee and IPH at Kilimanjaro Christian Medical University College (KCMUCo). 


\section{Competing interest}

The author declare that they have no competing interests.

\section{Abbreviations}

Cl;Confidence Interval,EC;Emergency contraception,ECPs;Emergency contraceptive pills,IPH Institute of Public Health,IUCD;Intrauterine contraceptive device,KCMUCO;Kilimanjaro Christian Medical University College,MDGs;Millennium development goals,MOCU;Moshi Co-operative University,MWECAU; Mwenge Catholic University,NFPCIP;National Family planning coasted implementation program,SMMUCo;Stefano Moshi Memorial University College,SPSS;Statistical Package for the Social Sciences,TDHS;Tanzania Demographic Health Survey, WHO; World Health Organization.

\section{References}

1. Mesfin D. Emergency contraceptive knowledge, utilization and associated factors among secondary school students in Wolkite town, southern Ethiopia , cross sectional study. 2020;4:1-10.

2. Ahmed FA, Moussa KM, Petterson KO, Asamoah BO. Assessing knowledge, attitude, and practice of emergency contraception: a cross- sectional study among Ethiopian undergraduate female students. 2012;1-9.

3. Town A, State OR, Menene A, Getachew A, Kediro A, Gutema B. Assessment of Knowledge , Attitude and Practice Toward Emergency Contraceptive Among Females Student at Unity. 2020;6(5):96-103.

4. Kgosiemang B. Emergency contraceptive knowledge, attitudes and practices among female students at the University of Botswana: A descriptive survey. 2011;1-6.

5. Beyene GA. Prevalence of unintended pregnancy and associated factors among pregnant mothers in Jimma town, southwest Ethiopia: a cross sectional study. 2019;(July).

6. Kara WSK, Benedicto M, Mao J. Knowledge, Attitude, and Practice of Contraception Methods Among Female Undergraduates in Dodoma , Tanzania Socio-demographic characteristics of respondents. 2019;11(4).

7. Singh V, Thakur P, Nayak P, Agrawal S. Knowledge attitude and practice (KAP) of emergency contraceptive pills among women of reproductive age group attending AlIMS OPD Raipur (C.G.). Int J Adv Med. 2014;1(2):1.

8. Kagashe GAB, Maregesi SM, Mashaka A. Availability, awareness, attitude and knowledge of emergency contraceptives in Dar Es Salaam. J Pharm Sci Res. 2014;6(1):15-8. 
9. Abyu GY, Zemene A. Evaluation of Awareness, Perception and Utilization Towards Emergency Contraceptive among Female Students in Private College at Bahir Dar , North West Ethiopia , 2014. 2016; (October).

10. West S. Knowledge, Attitude and Practice of Emergency Contraceptives among Pain Management \& Medicine. 2016;(December 2017).

11. Nyambura MG, Kiarie JN, Orang O, Okube OT. Knowledge and Utilisation of Emergency Contraception Pills among Female Undergraduate Students at the University of Nairobi , Kenya. 2017;989-1005.

12. Students F, Showa W, Lenjisa JL, Getachew ZG, Tola NL, Kifle ST, et al. Knowledge, Attitude and Practice of Emergency Contraceptives among. Res J Pharm Sci. 2013;2(May):1-5.

13. Feyissa A. Assessment of Knowledge, Attitude and Practice Towards Emergency Contraceptive Methods among Female Students in Abdisa Aga High School , Fiche Town , Northern ,. 2017;1(1):16-23.

14. M M, GamPatniit S, Damor R. Emergency contraception amongst medical college students: knowledge, attitude, practice Emergency contraception amongst medical college students: knowledge , attitude, practice. 2018;(November).

15. Lenjisa JL. Knowledge and Practice of Emergency Contraceptives among Students at Ambo Techniques College, Ethiopia. Reprod Syst Sex Disord. 2014;03(03). 